CP, 2020, Vol.9 - No19, pp. 109/122 ISSN 2014-6752. Girona (Catalunya). Universitat de Girona. GARCÍA MANSO; A. Almudena BARRIENTOS-BÁEZ y David CALDEVILLA-DOMINGUEZ: Cambios y continuidades en las representaciones del turismo y la sociedad en la tarjeta postal marroquí (1910-2016) Recibido: 07/10/2020 - Aceptado: 25/11/2020

\title{
Cambios y continuidades en las representaciones del turismo y la sociedad en la tarjeta postal marroquí (1910-2016).
}

\author{
Autora: \\ Almudena GARCíA MANSO \\ Universidad Rey Juan Carlos \\ Almudena BARRIENTOS-BÁEZ \\ Escuela Universitaria de Turismo Iriarte (Adscrita a la U. de La Laguna) \\ almudenabarrientos@iriarteuniversidad.es \\ ORCID: https://orcid.org/0000-0001-9913-3353 \\ David CALDEVILLA-DOMINGUEZ \\ Universidad Complutense de Madrid \\ https://orcid.org/0000-0002-9850-1350 \\ davidcaldevilla@ccinf.ucm.es
}

\section{Resumen}

Las tarjetas postales han sido artefactos culturales del turismo de masas, souvenirs y maneras de comunicación cuyos usos y sentidos son múltiples y variados. Como medio de comunicación, ya anacrónico o nostálgico, son objetos de un pasado que nos permite hacer un análisis histórico, visual y narrativo de cómo se retrataban los destinos turísticos, enfatizando el significado y sentido de lo exótico, la superioridad del occidente colonial y la fascinación por la aventura. Analizar sus cambios, es decir las transformaciones en las representaciones de ese destino turístico, cómo se ha ido alterando lo escenificado, suelen tener que ver mucho en cómo la mirada social del turista y del destino cambian, trastocando estos fragmentos de comunicación y narrativas de lo subjetivo. En esta aproximación cualitativa de las postales turísticas de marruecos (1890-2016), nos sugiere una revisión entre el desarrollo turístico y político del país, los cambios estéticos y de contenido representativo de la tarjeta postal y la mirada social hacia lo colonial y de colonial que se percibe en las representaciones de estos fragmentos de papel que, souvenirs o medios de comunicación, siguen teniendo un lugar como escaparate publicitario de un destino.

Palabras clave: Tarjeta postal, colonialismo, publicidad, representación, souvenir, imaginario social.

\section{Abstract}

Postcards have been cultural artifacts typical of mass tourism. They are, at the same time, souvenirs and ways of communication whose uses and meanings are multiple and varied. As a communication mean, anachronistic or nostalgic, they are objects of a past that allows us to make a historical, visual and narrative analysis of how tourist destinations were portrayed, emphasizing the meaning and sense of the exotic, the superiority of the colonial West and the fascination for adventure. Analyzing this changes, that is, the transformations in the representations of that tourist destination, how the staged has been altering, usually have a lot to do with how the social gaze of the tourist and the destination changes, disrupting these fragments of communication and narratives of the subjective. From a qualitative approach to the tourist postcards of Morocco (1890-2016), a review is made of the tourist and political development of the country, the aesthetic changes and the representative content of the postcard and the social gaze towards the colonial and decolonial that is perceived in the representations of these fragments of paper that, souvenirs or communication media, continue to have a place as an advertising showcase for a destination.

Key words: Postcard, colonialism, advertising, representation, souvenir, social imaginary. 


\section{Introducción}

La tarjeta postal de contenido fotográfico hace su aparición a finales del siglo XIX, un periodo dominado por la edad de oro de la fotografía. El evidente interés de la sociedad por un mundo que se expandía ante sus ojos y las influencias orientalistas, junto con el fuerte y marcado carácter colonial de la época, hacen de la tarjeta postal el vehículo ideal de la época. Un artefacto de múltiple uso, comunicativo, ideológico y panfletario, souvenir y recuerdo de un viaje o aventura y, como no, reflejo de una mirada social, la de ese momento, que sitúa al turista frente aquello que disfruta, ve y experimenta y que necesita dar a conocer.

La tarjeta postal nace en 1865 en Prusia. Heinrich von Stephan Consejero de Estado de Prusia propuso durante el Quinto Congreso Postal la circulación de cartas oficiales sin sobre, lo cual daba pie al primer esbozo de lo que después sería la tarjeta postal, una idea que quedó en el olvido sin que fuese puesta en marcha. No es hasta 1869 cuando Emmanuel Herman en Austria hace circular algunos fragmentos de papel franqueados, pero sin sobre, publicando posteriormente en el diario austriaco Never Freir Presse un artículo titulado "nuevo medio de correspondencia postal" (Sánchez, 1970). Esto levanto el interés de la Dirección de Correos y Telégrafos de Viena quienes promovieron una ordenanza real respecto a este nuevo medio de correspondencia. A partir de ese momento la primera tarjeta postal se editó bajo la forma de entero postal, un soporte rectangular impreso en negro y crema, constituido por un anverso y un reverso impreso en negro y crema. En el anverso estaba inscrito las palabras Correspondez-Karte, los escudos de armas del imperio austrohúngaro, el sello con la esfinge del emperador Francisco José I y un espacio dispuesto para la dirección del destinatario. El reveso incluía un texto donde la Dirección de los Servicios de Correos declinaba toda responsabilidad del contenido de la correspondencia (Ponce de León, 1968)

Poco después se extendió por el resto de Europa y por Estados Unidos. Es en este momento en el que los particulares comienzan a editar sus propias tarjetas lo cual obligaba a adherir un sello a la tarjeta postal (Hernández-Sampelayo, 1983). Esta edición particular y privada generó toda una amplia variedad de temas, acercándonos al sentir social, a sus problemas, preocupaciones, ideales y gustos. Más adelante las tiradas editadas profesionalmente sobre todo de impresores alemanes, franceses y norte americanos se encargaron de replicar no sólo los gustos de los usuarios sino los idearios y el discurso predominante del poder social. El hecho de incluir ilustraciones hizo que las tarjetas postales de edición privada desbancasen a la tarjeta postal estatal, la cual no tenía ningún tipo de ilustración. El desarrollo tecnológico junto con la creatividad de los ilustradores, impresores y particulares hizo que la tarjeta postal gozara de una aceptación mayor que la de las cartas y las tarjetas postales oficiales.

A partir de este momento la tarjeta postal pasa de ser un sistema de comunicación escrito popular a convertirse en un instrumento artístico y documental, utilizado para interés turísticos, militares, publicitarios, políticos, religiosos, morales, humorísticos y críticos entre otros. Propaganda en provecho del poder. En el caso de las tarjetas personales o privadas el anverso se reservaba para los sellos, la dirección y un breve espacio para la comunicación que, debido a su escaso espacio, en muchas ocasiones se continuaba escribiendo en el reverso, lugar reservado para la ilustración. Estas tarjetas se realizaban en su mayoría de papel rectangular acartonado e impresas en fototipia, litografía o fotograbado. Las dimensiones de las tarjetas solían variar. A partir de 1900 algunas de las postales se coloreaban, dejando a un lado el originario color negro y crema.

La historia de la tarjeta postal se ve atravesada por múltiples procesos históricos, sociales, ideológicos y 
técnicos que convergen contribuyendo en gran medida a fomentar e instalar el formato de la carta postal como un medio eficiente de comunicación, ágil, económico y significativamente estético. Uno de esos procesos socio históricos que debemos subrayar es el del desarrollo del turismo y la mirada colonial al destino, cómo esos imaginarios sociales, propios de un periodo concreto han marcado e imprimido un carácter y rasgo fundamental en las representaciones turísticas de esos fragmentos de papel, fundadas en una suerte de tópicos de lo exótico, lo salvaje, lo diferente y en ocasiones lo inferior, pero bajo el adorno y la representación ficticia y artificial de una cultura que es vista exógenamente (Burns, 2004; García-Manso y Martín Cabello, 2020; Cepeda et al, 2018)

En ese complejo entramado de procesos que atraviesan a la tarjeta postal y su relación entre comunicación, sociedad y turismo, deseo y expectativa del viaje y del viajero (Almirón, 2006; Urry, 1990), es imperativo recurrir al concepto de imaginario social colectivo (Castoriadis, 1985), esa creación incesante de figuras, formas o imágenes a partir de las cuales se hace referencia a algo en concreto, de manera grupal o individual. Imaginarios que son construidos a partir de las percepciones y del tratamiento subjetivo de los individuos pero que instituyen una narrativa que pasará al común, que imprimirá forma a esas percepciones y las perpetuará a través de la cultura, los idearios y los medios de comunicación de masas, quienes proporcionan cierta orientación en ese sentir del colectivo de referencia. Estos medios articulan estrategias de difusión de imágenes jugando con la imagenería social y cultural, simbólica e idearía que no siempre tiene una disposición de decisión y poder desde arriba, es decir desde los grupos de presión, hegemónicos o de poder, sino que estos imaginarios contienen en sí mismos una fuerza actante, es decir que contienen actitudes e intervenciones que los sujetos hacen de manera directa en su cotidianidad (Hiernaux, 2002; 2009), conteniendo diversos aspectos de vital importancia en su constitución y perpetuidad para un común y su tiempo, tanto presente como a futuro, estos aspectos vienen a ser las expresiones visuales o como es en nuestro caso las imágenes fotográficas de las tarjetas postales, las dimensiones lingüísticas que componen el relato, el mito o la transmisión escrita del reverso de la tarjeta postal y que acompañan a las imágenes y los procesos del pensamiento o las fantasías, ideas o idearios que tanto imagen como discurso evocan. Aspectos todos ellos presentes en nuestro objeto de estudio, y que sin ellos el sentido general del mismo dejaría de tener un sentido como artefacto cultural.

Un imaginario que en contexto turístico supone ser la porción del imaginario social referido a la experiencia o hecho turístico, a las manifestaciones de los procesos sociales del viaje, de la estancia y de las vivencias en el lugar de destino. La construcción de este imaginario es más compleja si cabe, queda sujeta a las impresiones y expectativas que son captadas durante una experiencia de vida y los deseos que pueden ser satisfechos durante el proceso turístico (Zamudio, 2011)

La fuerza de las imágenes frente al texto en el imaginario social es evidente por su espectacularidad y fácil recuerdo, más aún en espacios sociales como es el del turismo, donde el recuerdo está sujeto a vivencias y la publicidad hace uso de la imagen evocadora de esas vivencias expectantes (Zamudio, 2011).

A esta descripción del imaginario turístico deberíamos sumar aquella que lo describe como un proceso continuo más que un objeto estático, ya que se crea a partir de la imaginación y por ello es un proceso que permite crear, recrear, evocar y proyectar imágenes, símbolos y significados que sirven a modo de guía para dar forma y anticipar prácticas y experiencias, posibles, que los sujetos vivirán en su devenir como sujeto turista en el destino elegido (Fuentes Gómez, 2012). 
En este trabajo las tarjetas postales son los objetos transmisores y transmitidos del imaginario turístico y de la experiencia subjetiva, artefacto que albergará demasiadas dimensiones y sentidos, no sólo su dimensión comunicativa como medio, sino el sentido que posee y la carga ideológica de esas imágenes impresas en su reverso, figuraciones que en el caso que nos ocupan, las tarjetas postales del norte de áfrica colonial, están sujetas al imaginario colonial aun presente en algunas formas imaginarias del destino turístico (Rabascall, 2017; Mignolo, 2005; Hall y Tucker,2005; Boukhris y Peyvel, 2019). Tal vez los paradigmas postcoloniales y los decoloniales estén poniendo a prueba los imaginarios turísticos que se perpetúan.

Continuando con la tarjeta postal y sus múltiples funciones en el marco del turismo, debemos introducir el papel publicitario de la misma. Su presencia como objeto y souvenir que se emite y se colecciona, en el seno de la cultura turística, pues desde sus orígenes hasta nuestros días la emisión y el envío de estos "fragmentos" de cartón/papel fotografiado ha sido una actividad profusa y popularmente extendida, como un ejercicio ritual más del turista convencional (Rabascall, 2017). Es cierto que hasta la eclosión de la telefonía y el uso de las herramientas comunicativas de internet este era el medio de comunicación sin más, a partir de la popularización y abaratamiento de las llamadas internacionales, entre las décadas de los 70 hasta hoy, el acto de comprar una tarjeta postal y enviarla era, y sigue siendo, un ritual con multitud de sentidos y significados tanto subjetivos como sociales, uno de esos significados no es otro que el de demostrar la experiencia turística a los "otros remitidos", esos que no la han vivido ni experimentado. Pero no vamos a entrar en estas derivas, sino que nos centraremos en el análisis de cómo la tarjeta postal nos puede mostrar la evolución turística de un destino, los idearios que han marcado ese destino, sobre todo desde esa perspectiva de la colonialidad y el occidocentrismo del que la comunicación y la publicidad turística parecen no desprenderse del todo.

Esta aproximación exploratoria de abordaje cualitativo nos lleva a plantearnos los siguientes objetivos a considerar, analizar las posibles relaciones entre las representaciones que se proyectan en las tarjetas postales a análisis y su correspondencia con los imaginarios sociales, los estereotipos y los tópicos turísticos e idearios en el contexto sociohistórico concreto. Establecer una relación entre lo representado en las cartas postales y la evolución turística en contexto a análisis, poniendo el acento en la perpetuación o no de la mirada colonial como discurso narrativo que se derive de las representaciones fotográficas.

Como objetivo final se pretende considerar las tarjetas postales como artefactos que van más allá del ejercicio del recuerdo, la experiencia y la comunicación para erigirse como posibles soportes de comunicación publicitaria, adaptadas y adecuadas a los públicos y sus contextos.

Partimos de la hipótesis sobre el fuerte contenido simbólico y significativo respecto a la carga colonial en las representaciones turísticas y en su materialización cultural, como son los souvenirs y en este caso las tarjetas postales. Al tratarse del análisis de las tarjetas postales comercializadas en marruecos desde el periodo de 1910 hasta el 2016 nos encontramos ante un territorio que ha sido protectorado francés y español durante parte de ese periodo de tiempo, este hecho no es una mera anécdota o apunte histórico, sino que marca y sesga la disposición ideológica e idearía de las narrativas y discursos representados en las fotografías que componen los reversos de las tarjetas postales y de las cartes postales. Una influencia que fue desapareciendo paulatinamente tras la independencia de Marruecos en 1956, pero que se perpetúa y queda a modo de reflejo hasta la actualidad. 
Podemos contemplar cómo el desarrollo y apertura del país coincide con la atenuación de los sesgos y narrativas coloniales impresas en las postales, en función del progreso, industrialización, afluencia y profesionalización del sector turístico esas representaciones van tornándose en expresiones culturales más neutras y más occidentalizadas, eliminando determinados tópicos propios del imperialismo colonial y sus imaginarios (García Manso, Martín Cabello, 2020; Boëtsch y Villain, 2001).

Al hilo de lo anterior, no podemos olvidar que la evolución del sector turístico a partir del siglo XX en Marruecos han sido fluctuantes, acordes con sus cambios y políticas de desarrollo industrial, un país de larga tradición turística, pues su proximidad con Europa, su fama como mercado de especias, artesanías y otros productos procedentes de toda África, amén de la eclosión de la moda orientalista y la búsqueda de aventuras, hicieron de Marruecos un lugar de trasiego y tránsito turístico, militar y comercial, fomentando su fama y su posición como uno de los destinos claves, junto con Egipto, del turismo en el norte de África. Esa evolución discontinua inicia en 1918 cuando Marruecos crea el Comité Central de Turismo, aunque desde esas fechas hasta la reconstrucción de Agadir (tres años después de su independencia), el sector turístico se limita a unos servicios enteramente precarios, poco o nada profesionalizados y enfocados a dar servicio a militares, profesionales o agentes de los protectorados coloniales. Un periodo que podríamos denominar como de alta influencia europea e imperialista en el que, como veremos, la tarjeta postal es enteramente idearía y significativamente orientalista. Ya tras su independencia se inician ciertas políticas de desarrollo en el sector, pero extremadamente intermitentes, ejemplo de ello vemos cómo en las décadas de los 60 y 70 la inversión, promoción y construcción del sector y la industria turística era objetivo prioritario de la intervención estatal, ésta freno en seco durante las dos décadas posteriores, periodo en el que se produce un drástico retroceso y una privatización de los servicios y alojamientos hasta inicios del siglo XXI, dando paso a los planes Visión 2010 y 2020, permitiendo al estado retomar la agenda de desarrollo del sector (Almeida García y Chaine, 2016; Araque y Crespo, 2010).

Así mismo tampoco podemos olvidar la importancia comunicativa, publicitaria y cultural, como artefacto, de las imágenes en esas tarjetas y cartes postales, viaje, experiencia e imagen van íntimamente ligadas (Augé, 1998), adquiriendo un sentido que trasciende al mero hecho del ejercicio turístico, su capacidad de perpetuar y evocar, recrear y transmitir. El problema de ese recuerdo sentido está en la tesis que sugiere que toda fotografía ha de ser comprendida bajo un contexto determinado, pues imagen fotográfica y contexto son indisolubles, y el uno no puede ser comprendido sin el otro (Benjamin, 2004), es por esto por lo que el anverso de esas tarjetas, ese fragmento de texto que se añade, proporciona la magia de la experiencia narrada al remitente (Rabascall, 2017). La entremezcla de souvenir, publicidad y medio de comunicación proporciona a la tarjeta postal un valor ritual que comienza a desaparecer por la eclosión de las comunicaciones vía móvil y redes sociales.

\section{Metodología}

Abordar el análisis de las tarjetas postales del Marruecos colonial hasta casi nuestros días nos supone hacer un ejercicio de aproximación exploratoria, de carácter analítico y naturaleza cualitativa mediante el análisis fotográfico de los soportes a análisis. Un análisis cualitativo discursivo de las narrativas expuestas, siguiendo trabajos anteriores que se han fundamentado en el análisis de contenido cualitativo de estos formatos (García Manso, Martín Cabello, 2020; Rabascall, 2017; Gómez Barceló, 2007; Boulouque, 2005). La muestra seleccionada corresponde a la colección privada de la autora firmante en este trabajo, una muestra intencional y estratégica de un total de 95 tarjetas postales sobre Marruecos, datadas entre 1910 hasta el año 2016, y seleccionadas de un universo compuesto por 203 tarjetas postales. 
Explicar que no todas esas tarjetas postales fueron editadas en Marruecos, durante el periodo de los protectorados francés y español, una inmensa cantidad de esas tarjetas eran editadas en Francia, salvo excepciones editadas en contexto español. Ninguna de las tarjetas postales o carte postale giradas y editadas en ese periodo fue editada en Marruecos $u$ otros países ajenos al vínculo colonial e imperialista del momento, de ahí que uno de los aspectos fundamentales de las lecturas analíticas que se perciben es el sesgo colonial, con lo que eso conlleva en nuestro análisis. A partir de la década de los años 60 se comienza a vender y girar tarjetas postales de edición nacional, aunque perduran las ediciones francesas, continuidad que se mantiene activa hasta la fecha.

La muestra es intencional estratégica no supone arbitrariedad alguna o falta de rigor y objetividad alguna, esta intencionalidad detalla el desglose de las unidades a análisis divididas de manera tal que se relacionan con los periodos históricos que marcaron los cambios culturales, económicos y sociales en Marruecos, unos procesos tales que alteraron la cosmovisión del espacio colonial y sus representaciones en las tarjetas postales emitidas. Es así como el desglose corresponde a un conjunto de 25 tarjetas postales datadas entre 1910 y 1930, 25 tarjetas postales editadas entre 1931 a 1960, 25 tarjetas postales editadas entre el año 1961 al año 1990, 10 tarjetas editadas entre los años 1991 hasta el 2010, 10 tarjetas relativas al periodo posterior de 2011 hasta el 2016.

El primer grupo de postales analizadas corresponde a la época del protectorado francés y español, un periodo de fuerte influencia colonial e imperialista; el segundo grupo vendría a representar el periodo continuista del protectorado, la guerra del RIF y la guerra civil española, hasta la independencia de marruecos en 1956; el tercer grupo de postales abraca la fase inicial del desarrollismo marroquí con escaso fomento de la economía del turismo y la privatización de las infraestructuras hoteleras; el cuarto grupo de tarjetas postales responden al periodo de mayor desarrollo turístico que podríamos denominarlo como el despegue turístico de Marruecos y la etapa de los Planes Visión hasta el año 2016. El hecho de no analizar tarjetas postales que abarquen una fecha posterior al año de fin de nuestra muestra se debe al auge de las tarjetas digitales y el escaso mercado de la tarjeta postal contemporánea.

Divididas de este modo nos centramos a desglosar conceptos y variables de análisis en línea con los objetivos marcados, para establecer esta batería de unidades de medida nos fundamos, no sólo en trabajos ya citados y que han servido de antecedente, sino en lo que respecta al análisis del discurso social en contexto (Feliú, 2019; Morales Lezcano, 2006; Pérez Beltrán, 2001).

Tomamos de partida una serie de tipos y escenas que describen las postales de las dos primeras etapas, en contexto estaríamos hablando de las etapas de los protectorados francés y español, la guerra del RIF, la guerra civil española y el proceso anterior a la independencia Marroquí, un largo periodo de tiempo en el que las ideas de lo colonial, el poder del imperio europeo, las reminiscencias de la estética orientalista y los conceptos de raza, género y oriente serán claves a la hora de establecer líneas ideológicas diferenciales. Esos tipos de tarjetas vendría a estar representados en:

1. Mission y Missions des Pères Blancs. En estas tarjetas vemos la representación de la evangelización y la clemencia por los pobres salvajes (Shorter, 2011). Muestran las desiguales relaciones raciales, coloniales y religiosas frente al poder del estereotipo colono.

2. Nominales. Son aquellas que utilizan al pie de la tarjeta el nombre del personaje o su identificación.

3. Estereotipadas tipo. Centradas en las expresiones estereotipadas del otro, suelen estar acompañadas de un texto a pie de fotografía en el que de manera nominal se menciona explícitamente el 
rol del personaje con tintes peyorativos, como es el ejemplo de los adjetivos moro, negra, harem u odaliscas.

4. Folclóricas. En estas tarjetas se representan escenas prototipo del folclore, el espectáculo y la cultura de marruecos, en estas primeras etapas no están exentas de prejuicios y estereotipias sesgadas.

5. Étnico raciales. Aunque este tipo de tarjeta podrían ser incluidas como tipo nominal, es necesario establecer una distinción por su significancia. Dan muestra de sesgos y connotaciones claramente racistas y coloniales. En ocasiones son confundidas por tarjetas de carácter etnográfico o por tarjetas type

6. Urbanas. Representan obras urbanas y civiles erigidas durante el periodo colonial y post colonial. También es común encontrar entre este tipo de tarjetas espacios mestizos.

7. Paisajes, oasis, desiertos, vergeles o hábitats naturales de fuerte evocación orientalista y exótica.

8. Costumbristas o cotidianas. Son aquellas que exponen las actividades comunes y cotidianas del día a día. Centradas en escenas comunes o individuales, en las que las tareas que se desarrollan van desde usos y trabajos hasta el rezo, la oración o el ocio.

9. Presencia occidental sin mestizaje paritario: el autóctono aparece como sirviente, empelado, comercial o al servicio turístico del occidental.

10. Presencia occidental con mestizaje paritario: los personajes se entremezclan sin denotaciones ni distinciones.

11. Presencia únicamente occidental: sea de personajes o edificios, un tipo muy común en los últimos periodos del análisis.

12. Objetos típicos, elementos característicos de la cultura gastronómica y/o artesanías.

13. Políticas y o militares

Trece tipos o tipologías a considerar como variables entre las que no se incluirán las denominadas Type, pues bajo este tipo enunciativo de tarjeta se engloban tarjetas de tipo nominales, costumbristas, folclóricas y estereotipadas, de ahí que, aunque las mencionamos, no formarán parte de esta tipología, puesto que nos podrían conducir a equívoco y confusión y desdoblamientos no significativos. Se excluye de entre las tipologías aquellas que son de naturaleza propagandística política, tanto en el periodo de la guerra del RIF, la guerra civil española, el proceso de independencia y las coronaciones monárquicas, estas vendrían a representar un décimo cuarto tipo, no incluido en el análisis por su escaso valor turístico, aunque sí hemos incluido las políticas o bélicas pues se utilizaron como medios de comunicación durante esos periodos históricos.

Además de esta tipología que será utilizada a modo de variables conceptuales a análisis en la comparativa, vamos a tener en cuenta el método genético de Mannheim (1990) en cuanto a la división de las fases de la representación y el sentido de lo representado, consideraremos el sentido objetivo y su correspondiente descripción pre iconográfica -el reconocimiento de elementos y la familiarización general con técnicas de interpretación y representación-; el sentido expresivo y el correspondiente análisis iconográfico, las intenciones en cuanto a lo que se quiere expresar en la imagen; y el sentido documental y la interpretación iconográfica, la visión del mundo y los fenómenos culturales que se manifiestan en la imagen representada en la tarjeta postal.

\section{Resultados}

Podemos constatar un continuismo en la demostración de lo folclórico y lo natural, las artesanías y la esencia exótica de los edificios y vestigios de un orientalismo colonial, matizados en las dos últimas eta- 
pas, pero aún presentes bajo estereotipos y tópicos presentes en el imaginario colonial marroquí, ejemplo de ello lo encontramos en la recurrente representación de bazares, encantadores de serpientes, personas vestidas con atuendos típicos y la evocación al color y la arquitectura propia de marruecos.

Siguiendo los tipos anteriormente indicados podemos ver cómo periodo tras periodo se van replicando, perdiendo el sesgo peyorativo de las dos primeras etapas, aquellas que marcan una clara tendencia imperial y eurocéntrica, donde tanto personajes como naturaleza tienden a mostrar al autóctono como un sujeto dominado, colonizado, exótico o pobre. Estas etapas marcadas por la convulsión bélica y el protectorado contienen en sus representaciones figuraciones de la otredad colonial, la prostituta, el mendigo, el rezo del no evangelizado, los padres blancos o las casas de evangelización, las demostraciones raciales, étnicas y folclóricas, además de exponer la grandilocuencia de lo occidental -como ejemplo de desarrollo- frente a lo autóctono en un binario despectivo o aventurero. Periodos en los que muchas de esas cartas postales eran utilizadas por los destacamentos militares -franceses y españoles-, funcionarios de los protectorados, personas en busca de fortuna y negocios, además de aquellos que, guiados por los últimos coletazos de la fiebre aventurera propia del orientalismo, confiaron en las tierras africanas sus vivencias, aventuras y desventuras. No es extraño que las postales más giradas y utilizadas como medio de comunicación en esos periodos fuesen las postales de carácter erótico, muchas de ellas de un fuerte tono pornográfico. Este rasgo se fue perdiendo en función de la retirada de la población del protectorado y el advenimiento de las monarquías de un fuerte sentido religioso y moral, a pesar de lo cual sí que encontramos ciertos guiños a una sensualidad fotográfica, sobre todo en las tercera y cuarta etapa de la mano de las demostraciones de danza del vientre o de grupos de danzantes.

Estas exposiciones fotográficas marcan los pasos evolutivos hacia una publicidad turística más estética, cuidada y menos tópica, sobre todo en las dos últimas etapas, teniendo su máxima expresión en las postales del último periodo, donde no se hace muestra alguna de los peyorativos coloniales, la pobreza, el desequilibrio social y la omnipotencia occidental quedan desplazadas por una exposición de color, belleza y estética alusiva a los rasgos más folclóricos, característicos y propios de la cultura marroquí.

La siguiente tabla nos mostrará siguiendo los tipos, en consonancia con la metodología del análisis de la imagen y la fotografía en Mannheim y Benjamin, la evolución no sólo idearía, ideológica, de colonial y turística de estos soportes comunicativos que no dejan de ser medios y soportes publicitarios, a la par de fragmentos de las experiencias turísticas en una doble perspectiva, desde el punto de vista del que se representa, y de aquel que quiere mantener viva esa representación alusiva del viaje.

Tal y como se aprecia en el análisis de las tarjetas postales o carte postale, es más que evidente un cambio en la estética y la atenuada mirada colonial. La comunicación turística al uso y los imaginarios sociales que la atraviesan están ausentes en las dos primeras etapas, las representaciones del marruecos de esa época están en la línea de las narrativas coloniales del exotismo, el erotismo, la pobreza y subdesarrollo, la barbarie y cierto matiz orientalista como podemos contemplar en la imagen del tipo souvenir y en las eróticas. El paisaje en ese periodo se aleja de la búsqueda de un paraje de turismo de masas y se adentra en los discursos del exotismo de los vergeles y los oasis, con un matiz étnico cultural de diferenciación como es la imagen del rezo en el desierto, dispuesta en el tipo paisaje en la primera etapa. El tipo de postal que posee más peso y sesgo imperialista y discriminante es el de las postales nominales, aún habiendo seleccionado las más políticamente correctas y menos discriminantes, son un tipo de tarjeta postal de alto grado racista, peyorativo y con un fuerte peso ideario, propio del periodo de la colonización 
y protectorados. Este tipo de postales a diferencia de lo que nos podría parecer no desaparecen en la última etapa, quedando de tal manera que algo que se pretende representar como típico o autóctono termina siendo una exposición de sesgo colonial y racial.

La evolución de la comunicación publicitaria en estas tarjetas es clara si vemos cómo va cambiando las maneras de exponer los tópicos y estereotipos autóctonos, además de la presencia occidental. El cambio de tópicos es más que visible en las tarjetas de tipo paisaje, urbano, cotidianas, folclóricas y estereotípicas, en este último caso se pasa de una imagen fuertemente discriminante, como es una Type que representa a un mendigo, a una imagen que muestra un tópico sin apenas sesgo, una motocicleta -uno de los transportes más utilizados- en una plaza o zoco.

El hecho que desaparezcan las tarjetas eróticas y las de tipo político o militar supone un desapego de la etapa colonial y un avance hacia la idea de un país más moderno y neutral. En el caso de las tarjetas eróticas se debe tener en cuenta que estamos hablando de un país de religión musulmana y que esas imágenes -las de las primeras etapas- responden a un uso puramente colonial. Las incluidas en ese tipo en las tercera y cuarta etapa coinciden con el periodo en el que ese tipo de tarjetas, donde la mujer aparece insinuante en un contexto folclórico, eran interpretadas en otros países y culturas, el ejemplo de España sería el de las primeras postales en playas o ya del periodo del denominado destape. Estos tipos han ido, junto con las políticas y militares y las de tipo Mission desapareciendo a favor de una estética más acorde con la publicidad turística, la neutralidad y el gusto o corrección estética del momento.

La tendencia a la postal Souvenir y la inclusión de monumentos, artesanías, los paisajes más turísticos e incluso deportivos, o de "sol y playa", son claros síntomas de cómo la tarjeta postal, en estos contextos del pasado colonial, va pasando de ser un instrumento ideario del poder imperial y colonial, esa infopolítica del binarismo oriente-occidente-, a artefactos culturales, souvenir y soportes que comunican una experiencia turística más, aunque siempre resonarán los tambores de la mirada colonial. 


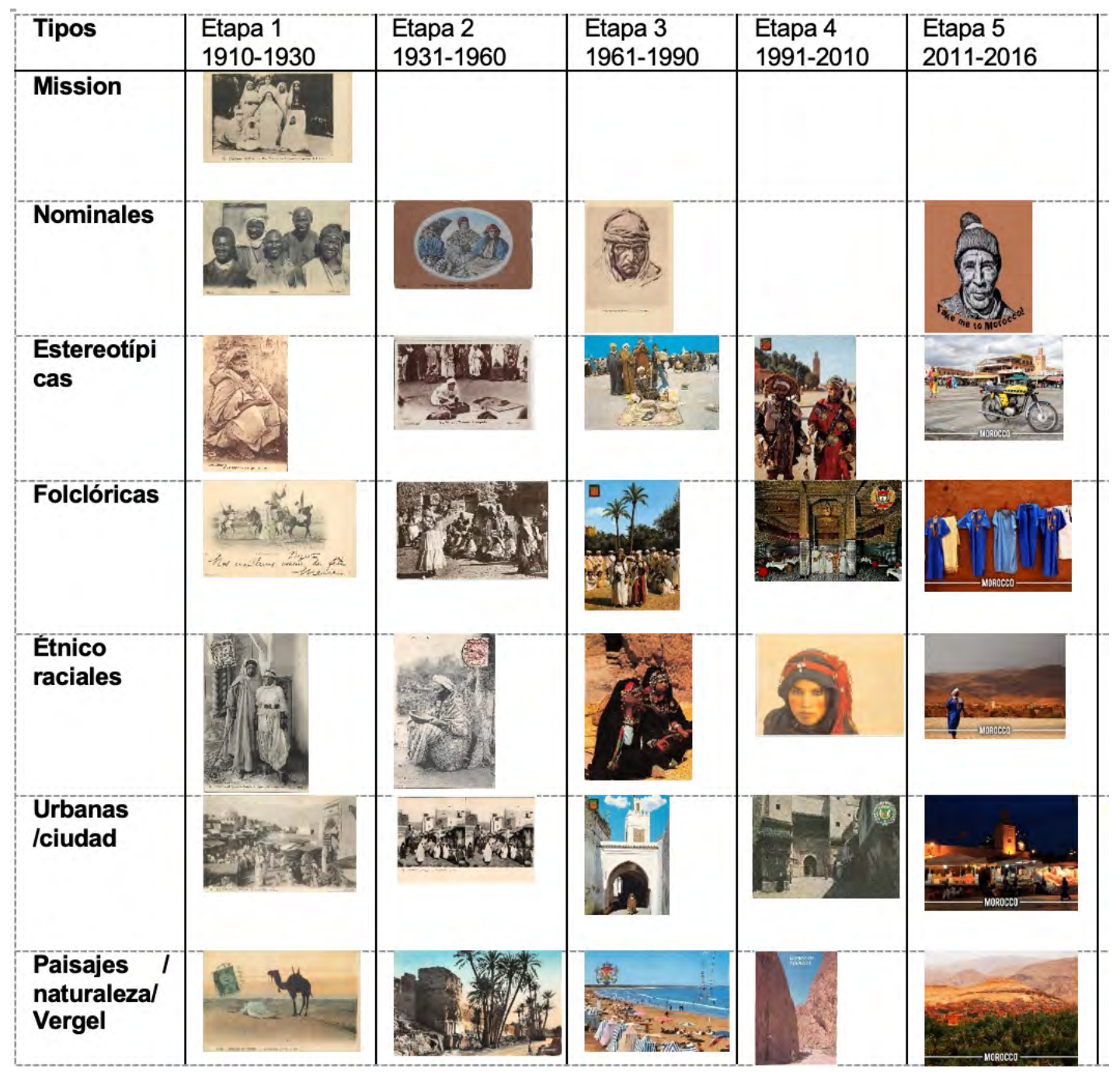




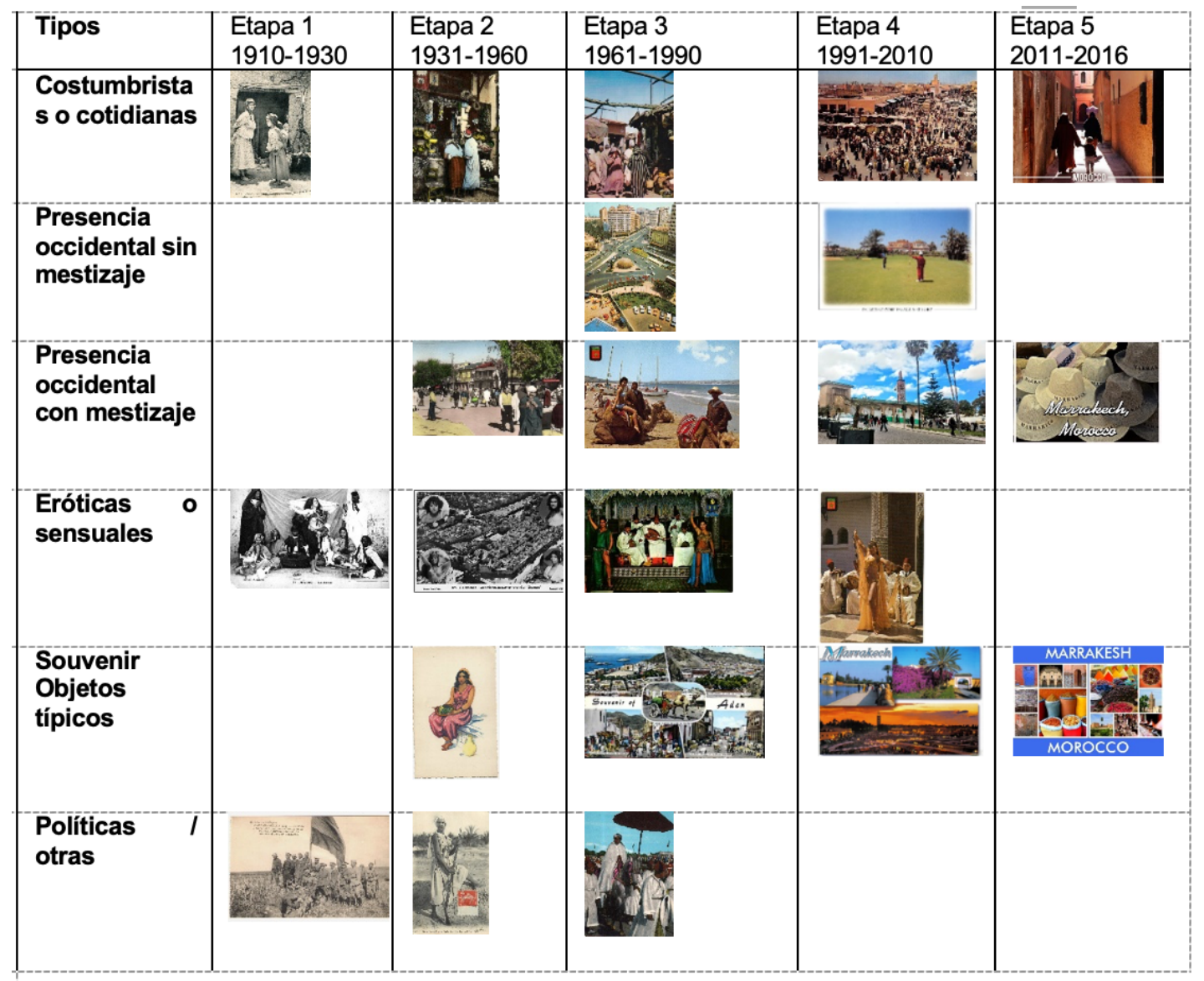

Tabla 1. Análisis por tipos. Elaboración propia,

Cartas Postales colección particular Almudena García Manso 


\section{Discusión}

Esta aproximación a las representaciones, tanto turísticas como sociales, de las tarjetas postales marroquís durante el periodo de 1910 hasta hoy en día nos descubre cambios y continuidades en nuestros imaginarios sociales a cerca de Marruecos como destino turístico y como sociedad. Utilizar las tarjetas postales supone hacer uso de un objeto común, de múltiples usos, tanto comunicativos como decorativos o souvenir, que se caracteriza por mostrar representaciones estereotípicas, pre conceptuadas y prejuiciosas, materializadas en escenas, muchas de ellas completamente teatralizadas y artificiales, de lo que podría ser el recuerdo de una experiencia turística o de un viaje realizado. Unas representaciones típicas que van más allá de la finalidad del objeto, la comunicación y el recuerdo de la experiencia del viaje. Las representaciones turísticas que representan estas tarjetas proyectan estereotipos y tópicos turísticos, como por ejemplo el tópico de las danzarinas y el del encantador de serpientes, los lugares comunes del turismo y de las narrativas coloniales como son los zocos o mercados, las calles bulliciosas, el color de las especias -así como la especia en sí misma-, las artesanías y la espectacularidad de un exotismo demostrado en las vestimentas, la selección de escenas, tipos o Types. En nuestros imaginarios el estereotipo de la Odalisca o el harem es un continuo evocado en multitud de postales de los dos primeros periodos, perpetuando hasta los grupos mixtos de danza de las tarjetas más comerciales de las décadas de los 70,80 y 90 del pasado siglo.

Entre esos tópicos y estereotipos que nos comunican y publicitan estos soportes artefactuales encontramos esa dicotomía occidente/oriente como desarrollo/retraso sobre todo en las demostraciones urbanísticas e infraestructurales de edificios, carreteras, obras o estancias hoteleras y de ocio que, en algunas postales se limitan de manera exclusiva a proyectar edificios o infraestructuras del sector turístico, deportivo y hotelero. Pero hay un choque que se perpetúa en este acervo imaginario que no es otro que el representado entre la mujer occidental -vestida como tal y en posición de turista- y el varón autóctono -vestido con la ropa típica y en una postura de complacencia, servicio e incluso mirada pícara-, un recurso que bien puede parecernos más humorístico que crítico esconde tras sí un sesgo que continua en la mirada de lo que otrora fue colonia. Este tipo de representaciones son comunes en las tercera y cuarta etapa, desapareciendo por completo en el último periodo.

Si nos fijamos en cómo se van diluyendo estereotipos y sesgos propios de esos periodos del protectorado y el imperialismo, el orientalismo y el exotismo propio de las primeras etapas, esas en las que el viaje mostraba idearía y panfletariamente una sociedad subdesarrollada, salvaje a la par que exótica, hasta llegar al punto de la etapa del desarrollismo turístico y el fomento del sector, las estéticas, el cuidado de la imagen, la búsqueda de la neutralidad y la publicitación de un país moderno pero con encanto, exótico y enfocado a un público que busca unas experiencias alejadas a esas miradas de lo colonial, sin olvidar como es obvio en toda comunicación y representación artefactual turística, los tópicos y folclores de una cultura.

\section{Bibliografía}

- Almeida García, F, Chahine, S. (2016). Evolución de la política turística y la intervención estatal. El caso de Marruecos, Cuadernos de turismo.38, pp. 13-37. http://dx.doi.org/10.6018/turismo.38.271331

- Almirón, A. (2006). Promoción turística y cartografía. La Argentina turística en los mapas de la Secretaría de Turismo de la Nación (1996-2004). Investigaciones Geográficas, (62), 138-157.

- Araque, E. y Crespo, J.M. (2010): Tourisme, territoire et environnement sur la côte mediterranéenne 
du Maroc, Cahiers de la Mediterranée, 81, 331-348.

- Augé, M. (1998). El viaje imposible: El turismo y sus imágenes. Barcelona: Editorial Gedisa.

- Baudrillard, J. (1997). La transparencia del mal. Barcelona: Anagrama.

- Benjamin, W. (2004). Sobre la fotografía. Valencia: Pre-Textos.

- Boëtsch, G; Villain Gandossi, C. (2001). Les stéréotypes dans les relations Nord-Sud: images du physique de L'Autre et qualifications mentales. Hermes, 30, 17-23.

- Boukhris, L; Peyvel, E. (2019). El Turismo bajo la óptica de los modelos postcoloniales y de la descolonización, Via Tourism review, 16. https://doi.org/10.4000/viatourism.4092

- Boulouque, C; Serfaty, N. (2005). Juives d'Afrique du Nord. Cartes postales (1885-1930). Paris: Bleu Autour.

- $\quad$ Burns, Peter. 2004. Six postcards from Arabia: a visual discourse of colonial travels in the Orient. Tourist Studies, 4, 255-275

- Castoriadis, C. (1985). La institución imaginada de la sociedad. Vol. 1. Barcelona: Tusquets.

- Díaz-Plaja, F. (1960). La historia de España en sus documentos: El siglo XX. Madrid: Graficas Faro.

- Feliú, L. (ed). (2019). Un siglo de movilización social en Marruecos. Barcelona: Bellaterra.

- Fuentes, J. (2012). Los imaginarios del turismo contemporáneo. Balance y perspectivas para la construcción del concepto. Essambles, 3, 153-175.

- García Manso, A; Martín Cabello, A. (2020). La mirada colonial "del otro" en las tarjetas postales del norte de África, 1900-1950, Revista Brasileira se Sociología da Emoção. 19(55).

- Gómez Barceló, J.L. (2007). Fotografía española en Marruecos: realidades soñadas, ensoñaciones recreadas. Mélanges de la Casa de Velázquez. 37 (1), 57-81.

- Hall, C.M., Tucker, H. (2005). Tourism and Postcolonialism, Contested Discourses, Identities and Representations. London: Routledge.

- Hernández-Sampelayo, J. (1983). Gracia y ventura de la tarjeta postal, en Boletín de la Academia Iberoamericana y Filipina de Historia Postal, 39, 142-143.

- Hiernaux, D. (2002). Turismo e imaginarios. Cuaderno de Ciencias Sociales. 123, 7-36.

- Hiernaux, D. (2009). Los Imaginarios del turismo residencial: experiencias mexicanas. En T. Mazón Martínez, R. Huete y A. Mantecón (ed.), Turismo, urbanización y estilos de vida. Las nuevas formas de movilidad residencial. Barcelona: Icaria.

- Holt, T; Holt, V (1971). Picture postcards of the Golden Age. A collector's Guide, London: MacGibbson \& Kee.

- Kyrou, A. (1975). L'âge d'or de la carte postale. Paris: Balland

- Mannheim, K (1990). El problema de una sociología del saber. Madrid: Tecnos.

- $\quad$ Mignolo, W. (2005). On subalterns and other agencies. Postcolonial Studies, (8)4, 381-407.

- Morales Lezcano, V. (2006). Historia de Marruecos, de los orígenes tribales y las poblaciones nómadas a la independencia y la monarquía actual. Madrid: La Esfera Libros.

- Pérez Beltrán, C. (2001). Una aproximación a la sociedad civil de Marruecos". Miscelánea de estudios árabes y hebraicos. Sección Árabe-Islám, 50, 231-252

- $\quad$ Ponce de León, L. (1968). La tarjeta postal documento histórico. Madrid: Gráficas Valera.

- Rabascall, J. (2017). Tarjeta postal y postal turística: Spain is diferent. SOBRE. 05, 113-132. doi:10.30827/ sobre.v5i0.9563

- $\quad$ Rapisarda, A. (1983). I/ mondo in cartolina 1898-1918, Milán: Rizzoli.

- Sánchez Albornoz, N. (1975). La progresión de la comunicación postal. Barcelona: Ariel.

- Shorter, A. (2011). Pères Blancs au temps de la conquête coloniale. Histoire des Missionnaires d'Afrique 1892-1914. Paris: Karthala. 
- Zamudio, L. (2011). Los Imaginarios en la percepción de los lugares turísticos. Imagonautas, 1(2), 114-137.

- Zepeda Arce, A; Medina Esparza, L.T; Bañuelos Hernández, M.C, (2018). Una mirada histórica a la construcción del imaginario turístico. Imagonautas, 12. 141-162.

\section{CURRICULUM VITAE}

\section{Almudena García Manso}

\section{Almudena Barrientos-Báez}

Doctor with an International Mention in Education and professor at the European University and Iriarte University School of Tourism, attached to the ULL (Tenerife-Spain). Master in Management of Protocol, Production, Organization and Design of Events - Communication area - (UCJC). Master in Management of Tourist Accommodation (Univ. Girona). Degree in Tourism (EUTI-ULL) and Teaching (Univ. Valencia). Journal editor Ciencias de la Comunicación e Información. It is part of the DEBATv project, televised Electoral Debates in Spain: Models, Process, Diagnosis and Proposal (CSO2017-83159-R), R + D + I (Challenges) project financed by the Ministry of Science, Innovation and Universities and the State Research Agency (AEI) of the Government of Spain, with the Support of the European Regional Development Fund (ERDF) of the European Union (EU). IP1 José Ruas Araújo. IP2 Ana Belén Fernández Souto. It is part of the project New values, governance, financing and public audiovisual services for the Internet society: European and Spanish contrasts (RTI2018-096065-B-E00) of research of the State Program of R + D + I orientation to the Challenges of the Society of the Ministry of Science, Innovation and Universities (MCIU), State Research Agency (AEI) and the European Regional Development Fund (FEDER). IP1 Francisco Campos Freire. IP2 Miguel Túñez López. Her main research interests are tourism, communication, education, social media, business management and intermediation, Protocol and Public Relations, emotional intelligence, and gender.

\section{David Caldevilla Domínguez}

Full professor at the Complutense University of Madrid. Bachelor and Doctor in Information Sciences, (U. Complutense). Diploma in Teaching (U. de Zaragoza). Two Sexenios (2006-2018). Teacher at: U. Complutense, U. Europea de Madrid, IED, ESERP and IPAM (Porto -Portugal-). Taught more than 20 subjects.

Speaker, lecturer and professor in several of his own titles (Telemadrid, Walter \& Thompson, McCann). Principal Investigator (I.P.) of the Complutense Research Group 'Concilium' ( $n^{\circ}$ 931.791). Researcher in 15 official research projects. Author of 6 books, 115 scientific articles in peer-reviewed journals and 77 book chapters. Director of 5 theses ( 2 with international mention). Member of scientific committees in numerous international scientific conferences and journals. Speaker at more than 120 international conferences. 